ORIGINAL ARTICLE

\title{
Mood Adjustment to Social Situations Through Mass Media Use: How Men Ruminate and Women Dissipate Angry Moods
}

\author{
Silvia Knobloch-Westerwick ${ }^{1} \&$ Scott Alter $^{2}$ \\ 1 School of Communication, Ohio State University, Columbus, $\mathrm{OH} 43210$ \\ 2 Communication studies, University of Michigan, Ann Arbor, MI 48109-1285
}

\begin{abstract}
Mood adjustment goals served to explain gender differences regarding media preferences. Before reacting to antagonism, females are likely to prevent aggression by dissolving aversive states through media consumption, whereas males could preserve aggression by choosing negative content. In a computerized procedure, participants $(N=86)$ were provoked by supervisor feedback to instigate angry moods. Half of the sample was led to anticipate a retaliation opportunity. In a purportedly separate study, participants were free to choose from online news while software unobtrusively logged their selective news exposure. The articles had been classified as positive or negative news in a pretest. When anticipating a retaliation opportunity, females spent more time reading positive news to dissipate their anger. Males expecting a retaliation opportunity spent more time on negative news to sustain their anger. Males' generally lower news consumption, especially when anticipating a chance to retaliate, indicated anger rumination through news avoidance altogether.
\end{abstract}

doi:10.1111/j.1468-2958.2006.00003.x

Americans appear to "waste" an astonishing amount of time each day on media exposure-more than 9 hours (Greenwald, 2000). It is often assumed that extensive media consumption helps individuals to escape from their daily hassles (Pearlin, 1959) or that they are "amusing themselves to death" (Postman, 1985). However, media use is often quite functional and facilitates adjusting to environmental requirements in emotional terms.

The interest of the current study is to extend research on mood regulation through media use by addressing (a) the motivations of media users' consumption of negative, upsetting content under certain circumstances, and (b) the use of media in adjusting personal mood states to meet social task requirements. Both phenomena are by no means rare but have not been accounted for in earlier research. It is argued that commonly found gender differences in mood management through media use can be explained by looking at these factors, because social norms differ by gender and may

Corresponding author: Silvia Knobloch-Westerwick; e-mail: Knobloch-Westerwick.1@osu.edu. 
thus instigate different mood adjustment behaviors in males and females. The current research seeks to provide theoretical rationale and empirical evidence to explain how and why male and female media users employ media stimuli differently to regulate their moods. It aims to complement existing theories, as well as elucidate earlier findings that have been called "bewildering and in need for an explanation" (Zillmann, 1988, p. 337).

\section{Challenges to mood management theory:}

\section{Gender differences and exposure to negative content}

The dominant approach to the regulation of affective states within communication research was postulated by Zillmann (1988), whose mood management theory suggests that individuals employ media messages to regulate their moods in the interest of bettering their feeling states. The theory has been demonstrated to explain selective exposure to entertainment fare in numerous studies (for an overview, see Knobloch-Westerwick, in press). Yet, the theoretical proposition of mood management theory has also faced some challenges (Zillmann, 2000) that inspired the current research. Specifically, the common use of negative, upsetting media content contradicts the theory's assumptions. Particularly women seem to enjoy tragedies (Mills, 1993; Oliver, 1993; Oliver, Weaver, \& Sargent, 2000), and men tend to prefer horror (Oliver, 1994). Generally, gender differences occur in many investigations on mood management patterns (Oliver, 2003) and are frequently observed in media effects research (e.g., Oliver, Sargent, \& Weaver, 1998; Oliver, 2000).

Work by Biswas, Riffe, and Zillmann (1994) provides a good example of such gender differences in media selection patterns. These authors examined news preferences of individuals depending on their mood states. Participants were placed in either good or bad moods and could then choose 6 of 12 news articles that they wished to read. These articles had been classified as either positive or negative news in a pretest. The authors found that women in a bad mood preferred positive news content, whereas women in a good mood more often selected negative news content. However, this pattern was not found for males: "In stark contrast, men in a negative affective state tended to select more bad news than did men in a positive affective state" (Biswas et al., 1994, p. 693).

\section{Gender differences in anger regulation strategies}

A plausible interpretation of these gender differences in the findings by Biswas et al. (1994) is that the mood induction used in this study may have provoked participants as they received personal negative feedback from an experimenter. Males may have aimed to maintain their angry mood for later retaliation upon the provoker (O'Neal $\&$ Taylor, 1989). Females, on the other hand, are generally less aggressive than males (Brody \& Hall, 1993) and might have simply sought to dissipate their hostility through consumption of positive content. This interpretation, however, implies departing from the parsimonious conceptualizations inherent in mood management theory. Individuals may employ media content differently-depending on more specific categories of affect, such as anger, and on mood regulation intentions 
other than mood optimization. The interpretation above furthermore suggests gender as a factor that plays into mood regulation with media content.

Our reasoning about Biswas et al.'s (1994) findings falls in line with results from Rusting and Nolen-Hoeksema (1998), which indicated that women use distraction as a mood regulation strategy to avoid feelings of anger. Other studies (Frodi, 1978) have shown that men tend to ruminate about anger and aggression. A study by O’Neal and Taylor (1989) actually attests to males' motivation to maintain anger if they anticipate an opportunity to retaliate upon the provoker. The authors suggested that participants aimed to reduce their anger via media use when no chance to get even was expected; in contrast, provoked males anticipating retaliation wished to prolong their anger by using violent content. For retaliation, an angry mood is more functional and the mood enhancement may just be delayed and pursued later via reprisal. As for the study by Biswas et al., the same explanation can apply to results from other studies (Masters, Ford, \& Arend, 1983; Medoff, 1979).

\section{Mood adjustment approach}

The behavioral patterns observed in these studies call for a theoretical explanation. This perspective should clarify why media users do not always prefer uplifting content and how media use may serve to adjust personal mood states to their desired performance for upcoming social situations. For instance, it appears as if the males in the studies cited above sought to maintain an angry mood because they wanted to retaliate eventually. In order to explain such anticipatory regulation patterns, the mood adjustment approach has been developed (Knobloch, 2003).

The mood adjustment approach (Knobloch, 2003) suggests that individuals aim to regulate their moods in order to meet the requirements of anticipated situations. Thus, they engage in media consumption that helps to set the desired mood. The requirements triggering mood adjustment may consist of individual working tasks or social situations, in which composure or even sadness appears appropriate. Examples, such as wanting to be focused during an exam and desiring to possess composition and composure while driving during rush hour, demonstrate circumstances when it would not be appropriate to be in a happy, energetic mood. Depending on situational adjustment goals, individuals may prefer media content that impairs the hedonic quality of their mood but helps them to focus on a task or to display, if not fully experience, socially desirable emotions. Given the importance of anticipations in this perspective, developments in media use over time are considered crucial.

Supporting evidence (Knobloch, 2003) has been presented based on a procedure in which anticipated tasks were to be performed individually. Yet, oftentimes the anticipated tasks and activities that trigger mood adjustment behavior are social in nature. Such mood adjustment has been investigated by Erber, Wegner, and Therriault (1996), whose findings demonstrate that people aim to adjust their affective states by selecting media content. However, these results are impaired by the contrived nature of the selective exposure measures: Participants were asked to go through a list of news article headlines and rank them to indicate their preferences, 
but actual news exposure did not occur. The current investigation examines mood adjustment with a more natural media selection situation. Furthermore, we focus on processes of mood regulation over time.

Based on the considerations above regarding gender differences in mood management patterns, the present investigation will address mood adjustment to a social task that is perceived as a provocation repercussion, involving coping with anger specifically. After facing antagonism, females are likely to pursue such a collected state (Brody \& Hall, 1993) as aggressive behavior is generally less acceptable for them according to social norms. Males, on the other hand, are more likely to seek a state that is functional for retaliation (Brody, 1993; Brody \& Hall) and may thus prefer material that helps to maintain anger. It should be noted that individuals are often unaware of their mood adjustment intentions. Thus, unobtrusive observations of behavior-selections of media content with selective exposure measured across time-are to be preferred over introspective data. The amount of time media users dedicate to exposure to different types of content indicates their mood adjustment efforts. Positive and negative news will serve as material that helps to either dissipate or maintain angry moods. Hence, different adjustment intentions can be pursued with the offered stimuli, and these intentions are then indicated in the analysis by the observed selective exposure time dedicated to these stimuli. The valence differentiation will be based on comparative classifications as news is not positive or negative in absolute terms. The following hypotheses are subject to empirical test, along with a research question on how the intensity of angry moods may mediate these effects.

$\mathrm{H}_{1}$ : (a) Females who anticipate an opportunity to retaliate against the provoker of angry moods aim to enhance their moods and spend more time on positive media content than females who do not anticipate a retaliation opportunity; (b) males who anticipate an opportunity to retaliate against the provoker of angry moods aim to sustain their moods and spend less time on negative media content than males who do not anticipate a retaliation opportunity.

$\mathrm{H}_{2}$ : (a) Females who anticipate an opportunity to retaliate against the provoker of angry moods aim to dissipate their moods through distraction and spend more time on media content than females who do not anticipate a retaliation opportunity; (b) males who anticipate an opportunity to retaliate against the provoker of angry moods aim to sustain their moods and spend less time on media content than males who do not anticipate a retaliation opportunity.

$\mathrm{RQ}_{1}$ : Do the effects postulated in $\mathrm{H}_{1}$ and $\mathrm{H}_{2}$ depend on the intensity of moods?

\section{Method}

\section{Overview}

In the first part of a web-based experiment, participants were assigned to either light or heavy levels of provocation to instigate low versus high levels of anger. For this 
purpose, they ostensibly took an "emotion recognition test," for which feedback was assigned based on experimental condition. Participants were led to believe that the session's supervisor was the provoker providing the negative feedback and, depending on condition, that retaliation effort would be possible against the supervisor (anticipation of retaliation: yes vs. no). In what was purportedly a second study, all respondents browsed through an experimental online newsmagazine for an equal amount of time. This newsmagazine featured six positive news reports and six negative news reports, for which valence differentiation had been established in a pretest. Selective exposure to positive and negative reports was unobtrusively logged via software to observe mood adjustment efforts. Finally, participants provided feedback of the performance of the supervisor and quality of the articles.

\section{Experimental design}

The experimental $2 \times 2 \times 2$ design employed three between factors with two levels each: sex (male vs. female), anticipated retaliation opportunity (yes vs. no), and anger level (low vs. high). Repeated observations of selective news exposure across time, with six intervals of 30 seconds each, served as dependent variables. Selective exposure was furthermore differentiated by valence of the consumed news reports (exposure to positive vs. negative news). Hence, time and valence both served as within factors, resulting in 12 measures. This experimental design provided an analysis of variance (ANOVA) approach to address both hypotheses and the research question simultaneously. In addition, self-report data were collected and analyzed for treatment checks and to explore how mood adjustment efforts actually affected later behavior.

\section{Respondents}

Eighty-six students enrolled in introductory communication studies courses at the University of Michigan, Ann Arbor, served as respondents (49 females and 37 males). The average participant age was 20.2 years $(S D=1.3)$. Cell sizes ranged between 9 and 13. The software ensured equal proportions of males and females in each experimental group. Participants received financial compensation for their participation.

\section{Procedure}

Participants convened in a reception room, and a male supervisor distributed the consent forms. Although it is possible that the gender of the supervisor mattered in the given situation, the experimenter remained constant for all conditions. After the consent forms were signed, the supervisor instructed the participants to quietly enter the computer laboratory, have a seat at a computer, and follow the directions on screen. The supervisor also stated that he would remain in the reception room to monitor the session's progress from his computer there. Sessions consisted of up to 12 participants as the laboratory contained 12 identical workstations residing in partitioned cubicles. Keyboards were removed from the computers, leaving only a 17 " LCD monitor and mouse on each desk. The resolution of the screens was set to $1024 \times 768$ pixels. The computerized procedure was created using the programming 
languages PHP, JavaScript, and HTML. Throughout the procedure, all the participants' actions were logged onto a MySQL database server.

All screens initially displayed a questionnaire asking for demographic information (age and gender). Upon data entry, participants were instructed as follows: "Thank you for participating in this research session. It consists of two different studies. The first one is an emotion recognition test. The second asks about your impressions from an online news platform." All web pages in the first section of the procedure were headed with the title "Study 1" in large white text on a red horizontal bar to reinforce the perception that the session consisted of two different studies. Then, participants took an emotion recognition test, consisting of pairing 20 images with one of six emotions listed. After responding to all 20 images they were shown a results table, and after 30 seconds a feedback message from the supervisor was displayed. Participants then clicked a button to proceed to the next study.

The web pages in the next section contained the header "Study 2" in large white text on a blue horizontal bar. Instructions indicated that a test version of an online magazine would be displayed and the participant should browse through it and read any articles of interest. They also were informed that time would not permit them to read everything so they were to "pick and choose," and after a while a questionnaire would be displayed automatically. Upon clicking the button to continue, participants could browse through the online newsmagazine for $4 \mathrm{~min}$.

After time expired, the screen automatically advanced to a feedback form that served to collect ratings of the supervisor's performance. Finally, the online articles were evaluated with another computerized questionnaire to provide closure. The last screen page instructed participants to quietly exit the lab and see the supervisor. They received a debriefing form and compensation for participation.

\section{Anger manipulation}

To manipulate their anger levels, participants took an emotion recognition test. The procedure was adapted from earlier research on mood management (Biswas et al., 1994; Knobloch, 2002; Knobloch \& Zillmann, 2002; Zillmann, Hezel, \& Medoff, 1980). The instructions on the screen stated

This first task is a test to assess your sensitivity to facial cues associated with particular emotional expressions. This test has been devised by Professor of the

University of one of the world's leading authorities on facial expressions. The measured sensitivity is a crucial skill in human interaction. A person who is deficient in this skill lacks empathic sensitivity, which greatly handicaps him/her in achieving desired ends in interacting with others.

Respondents were shown portrait photos with highly ambiguous emotional expressions on the left side of the screen, each image for 2 seconds. Then, on the right side of the screen, six emotions (anger, fear, sadness, disgust, happiness, and surprise) were labeled on buttons to be clicked. Once the participant selected an emotion label, 
the buttons disappeared and the next facial image appeared on the left side of the screen. This repeated for 20 pictures.

Outcomes of this test were predetermined based on the anger-level condition previously assigned. Upon completion, the screen prompted with "You have completed the emotion recognition test. Please look over your results while the supervisor does the same. You will receive a response from the supervisor shortly." A table on the screen listed each image number followed by "Right" (which appeared in a green font) or "Wrong" (which appeared in a red font), depending on the supposed accuracy of the participant's responses. For low anger, participants scored 11 out of 20 correct, and participants assigned to the high-anger condition scored three correct. After a 30-seconds delay, the page advanced and contained a predetermined message from the supervisor, which seemingly was just entered by the supervisor sitting at a computer in the reception room (similarly, O'Neal and Taylor, 1989, among others, used experimenter feedback as a provocation treatment).

Participants received the following message in Courier font in a designated onscreen box that varied depending on condition-\{low anger $\}$ (high anger): "You answered $\{45\}$ (85) \% of the questions wrong. The results of your test were $\{$ poor $\}$ (worthless). This reflects your \{fairly weak $\}$ (unusable) social skills because you $\{$ do not have (totally lack) the ability to recognize others' emotions." This message, apparently from the supervisor, was to provoke the participants to desire retaliation against the supervisor.

\section{Anticipation of retaliation}

Modeled after O’Neal and Taylor's (1989) study, an announcement that the participants would eventually evaluate the supervisor's performance indicated a later opportunity to retaliate. For participants who were to anticipate retaliation, the very first instruction screen before the emotion recognition test stated, "Because our quality assurance policy requires that you evaluate the supervisor of this study, you will be presented with a form to do so at some point during the session." This message was basically repeated after the newsmagazine browsing instructions. Those who were not to anticipate retaliation did not receive either message.

\section{Online news platform}

The experimental newsmagazine featured a typical layout of an online news web site- with a title across the top of the page, a sidebar down the left side, and the page content in a main frame on the right side. The links on the sidebar were disabled. In the main frame on the overview page, news leads were displayed in six rows and two columns, with headlines and the first 10 words from each report. The arrangement of the news leads was constant and mixed good and bad news, so that newsreaders would equally come across both kinds of content. Participants could click on the titles to view the full text of the articles. To go back to the overview page, participants could click on links at the top and bottom of the articles. 
The 12 news stories were taken from issues of Time, Newsweek, and U.S. News and World Report. Articles chosen were the same as used and pretested by Biswas et al. (1994). These authors had classified half of these articles as good news and half as bad news, with all articles scoring equally high on the item "interesting." Good news articles received high ratings on a hedonistic valence scale, contrasting the lower scores of the bad news articles. Thus, the provided stimuli were clearly differentiated by the mood-impacting attribute of hedonic valence (Zillmann, 1988), but homogenous in their absorption potential. In the original study by Biswas et al., only the first page of the magazine article had been presented to respondents. For the purpose of displaying these texts in an online news platform, all original articles were edited to be of similar lengths $(M=471$ words, $S D=5.5)$. It is important to note that all news stories featured content that appeared still current (such as Gulf War, AIDS, President Bush, famine in the Sudan) once adjusted for a few minor details in the text (e.g., year).

\section{Dependent measures}

\section{Selective exposure measurements}

During the news browsing, the software unobtrusively logged the beginning and ending times when participants accessed article pages. This information allowed the derivation of selective exposure times by article and for time intervals during the browsing period. More specifically, the exposure to positive and negative news in seconds was accumulated and recorded for each 30-s interval of the browsing period (similar to studies by Knobloch, 2002/2003, and Zillmann, Chen, Knobloch, \& Callison, 2004).

\section{Supervisor evaluation}

Respondents rated the supervisor based on the question "How strongly would you recommend to keep this person doing this job?" (5-point scale from not at all to very much) after they had given specific impressions using the items considerate, helpful, aggressive, meticulous, rude, and understanding (5-point scale from not at all to extremely). The procedure did not collect data on whether participants anticipated an opportunity to evaluate the supervisor, because a corresponding question would have seemed awkward and produced contrived response scores.

\section{News evaluation}

Participants evaluated the reports on a 5-point scale from not at all to extremely for the adjectives newsworthy, enjoyable, interesting, depressing, and relevant. The question "How much did you like the article selection?" was also answered on a 5-point scale from not at all to very much. These questions served to provide closure to the participants. 


\section{Results}

\section{Manipulation checks}

To assess the effectiveness of the anger-level treatment, an ANOVA was conducted with the anger manipulation as between factor and scores for the question "How strongly would you recommend to keep this person doing this job?" as the dependent measure. Participants in the "high-anger" experimental group gave significantly worse ratings $(M=3.76$ vs. $4.23, S D=.98$ and $.77 ; F(1,84)=5.98, p=.017$, $\left.\eta^{2}=.07\right)$, which indicates different levels of anger created by the treatment.

The manipulation of anticipated retaliation opportunity had been adopted from O’Neal and Taylor (1989) and was also similar to treatments employed by Zillmann and Cantor (1976) and Thompson and O'Neal (1987). It produced effects in all these studies, although none employed a treatment check specifically on the anticipation, probably because a related question would appear peculiar. Nonetheless, to investigate effects of the repeated announcements on upcoming supervisor evaluations in the group with anticipated retaliation opportunity (compared to no announcements of this kind in the other group), it was examined how much the participants felt that the news reports had been cognitively engaging and important. If participants held the anticipation, this should slightly reduce cognitive engagement with news. Indeed, the group that anticipated a retaliation opportunity found the news reports generally less newsworthy and less relevant, $M=3.5$ vs. $4.1, S D=1.1$ and .88 (newsworthy); $M=3.1$ vs. $3.5, S D=1.0$ and 1.2 (relevant); $F(1,84)=6.1, p=.016, \eta^{2}=.07$ in an ANOVA with repeated measures. No effects of the announcements were found for the other news evaluation items, which referred to aspects of enjoyment.

\section{Impact of gender, anger level, and anticipated retaliation opportunity}

\section{on selective exposure to good and bad news}

To address both hypotheses and the research question simultaneously, an ANOVA was conducted with a $2 \times 2 \times 2$ mixed-model design, applying retaliation anticipation (opportunity anticipated, yes vs. no), gender, and anger level (low vs. high) as between factors and exposure to positive and negative news across time intervals of 30 seconds as within factors. Six 30-second intervals after the first browsing minute were analyzed, 12 in total, because of the differentiation between positive and negative news. The first minute was excluded from further analyses, because it did not yield much variance in terms of news exposure as a large amount of time was generally dedicated to orienting on the overview page ( $44 \%$ of the time compared to $10 \%-14 \%$ for later intervals).

With regard to $\mathrm{H}_{1}$, this ANOVA yielded an interaction between the factors of gender, retaliation anticipation, and valence and time, $F(5,390)=4.15$, GreenhouseGeisser-corrected, $p=.009, \eta^{2}=.051$. Figure 1 displays exposure to good news only - which is almost the exact inverse of exposure to bad news-based on estimated marginal means. The genders differed in their selection behavior across time, depending on whether participants anticipated the opportunity to retaliate or not. 


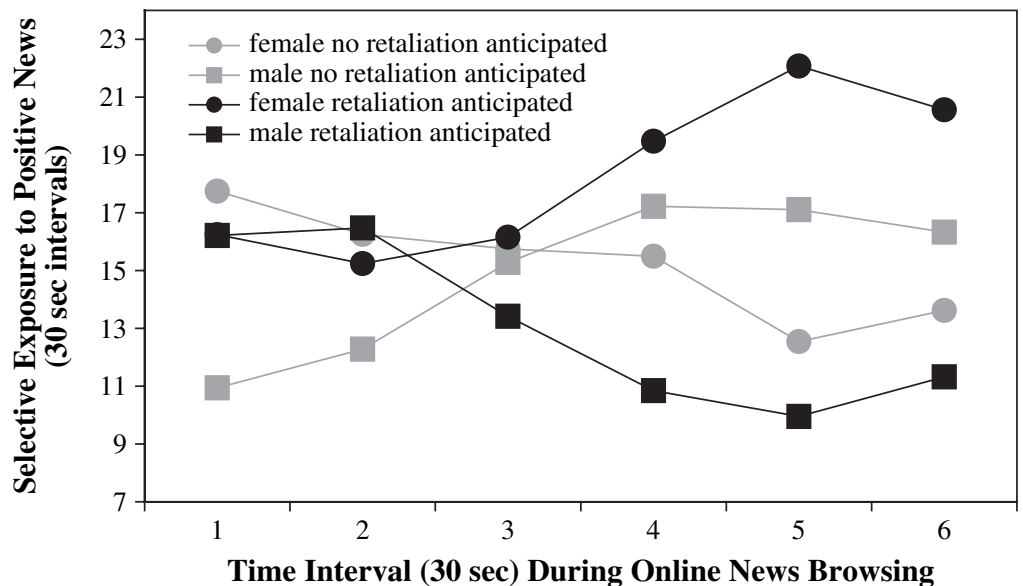

Figure 1 Selective Exposure to Positive News Across Time as a Function of Gender and Anticipated Retaliation Opportunity.

Although online readers who did not anticipate any retaliation did not show strong changes across time in both genders, within those who anticipated retaliation, males and females showed notably different patterns. Males anticipating retaliation spent decreasing portions of their reading time on positive news, whereas females anticipating retaliation did the opposite by increasing exposure to positive news.

With regard to $\mathrm{H}_{2}$, an interaction between anticipated retaliation opportunity and gender emerged, $F(1,78)=3.07, p=.08, \eta^{2}=.04$. However, this interaction was only marginally significant. Males who anticipated a retaliation opportunity tended to dedicate less time to actually browsing article pages instead of looking at the front page ( $M=150$ vs. $159 \mathrm{~s}, S D=24$ and 14$)$. Females' total news exposure was not affected by the anticipated retaliation opportunity $(M=161$ vs. $163 \mathrm{~s}$, $S D=11$ and 11). Females, however, generally spent more time on reading the articles instead of looking at the front page than males did $(M=162$ vs. $154 \mathrm{~s}$, $S D=10.9$ and 20.2). This was indicated by a significant main effect of gender, $F(1,78)=5.20, p=.03, \eta^{2}=.06$.

With regard to $\mathrm{RQ}_{1}$, the level of anger did not produce any significant effect. A power analysis (Cohen, 1988) with G*POWER (Erdfelder, Faul, \& Buchner, 1996) showed that a small effect (i.e., .02) of anger level did not have a sufficient likelihood to be detected in the ANOVA with repeated measures, indicated by power levels less than .25 for the various possible effects. However, for a moderate effect size (i.e., .15), power would have been sufficient at .80 .

Furthermore, the ANOVA showed that the valence of the articles resulted in differing lengths of selective exposure, $F(1,78)=5.52, p=.021, \eta^{2}=.07$, as participants generally spent more time on positive articles compared to the negative reports $(M=93$ vs. $66 \mathrm{~s}, S D=51$ and 50$)$. No other effects in this ANOVA approached significance. 


\section{Supplementary analyses}

In order to see whether mood adjustment efforts actually affected later behavior, effects of exposure to positive and negative news on the supervisor evaluations ("How strongly would you recommend to keep this person doing this job?") were examined.

This examination, however, required the following preparation. The ANOVA reported above had shown that mood adjustment efforts itself, represented by news exposure, was influenced by gender and anticipated retaliation opportunity and that participants especially varied in their news exposure during the last four browsing time intervals (as the supervisor evaluation approached). Hence, in order to detect only mood adjustment effects on later behavior, influences from gender and anticipated retaliation opportunity were excluded by saving residuals from two ANOVAs with gender and anticipated retaliation opportunity as between factors. Furthermore, these ANOVAs employed exposure to positive news and to negative news during the last four accumulated intervals as dependent variables, because the news browsing was probably of greater importance for the behavior immediately afterward. The ANOVAs both yielded significant interactions for gender and anticipated retaliation opportunity, $F(1,82)=7.80, p=.007, \eta^{2}=.09$ for positive news exposure; $F(1,82)=4.98, p=.028, \eta^{2}=.06$ for negative news exposure. These outcomes are depicted in Figure 2.

The residuals from exposure to positive news were significantly correlated with supervisor evaluations $(r=.22, p=.041)$, and the correlation between residuals from negative news exposure and evaluations was marginally significant $(r=-.18, p=.10)$. Hence, the mood adjustment efforts, as indicated by selective

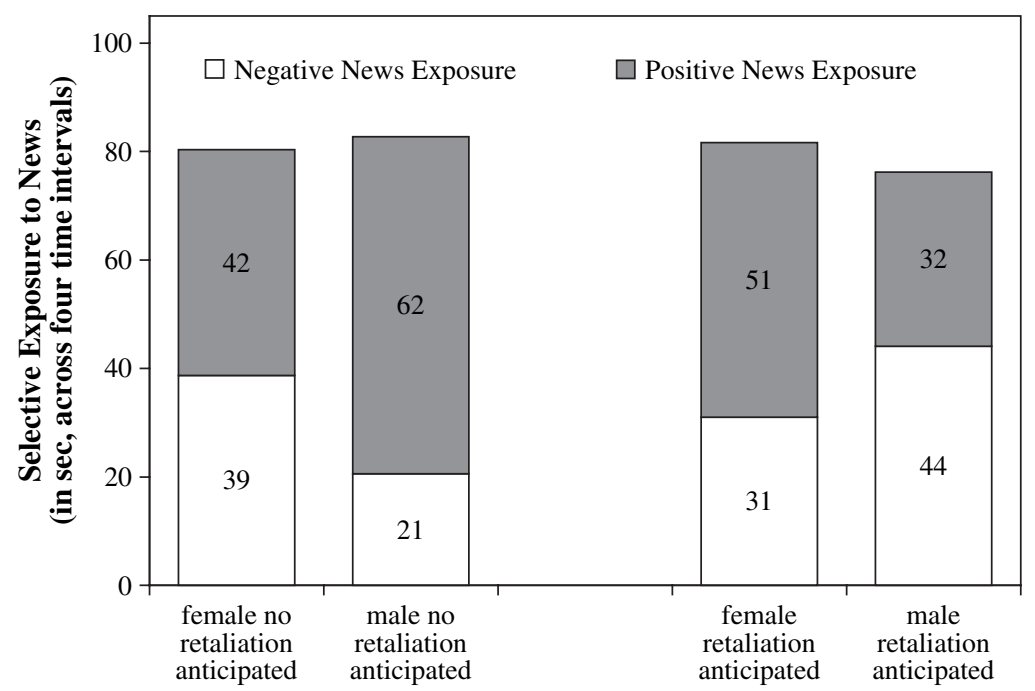

Figure 2 Selective Exposure to News as a Function of Gender and Anticipated Retaliation Opportunity. 
exposure to positive and negative media content, indeed affected behavioral outcomes in a social situation. Efforts to enhance one's mood through longer exposure to positive news resulted in more favorable evaluations of a provoker. On the other hand, maintaining anger through consumption of more negative news tended to result in a worse assessment of the provoker.

\section{Discussion}

Mood management, in the sense of mood optimization, has been demonstrated to govern media selections. However, empirical findings contradicting the theory could result from different mood regulation goals pursued during media exposure. According to the mood adjustment approach, individuals aim to set their mood depending on upcoming situations or tasks. For example, males, more often than females, may wish to act assertively. Females, on the other hand, tend to avoid such behavior. Most likely due to socialization and gender stereotyping of emotional expression, and not because of gender-specific emotional experiences (Plant, Shibley Hyde, Keltner, \& Devine, 2000), the genders often pursue different mood states, resulting in different media preferences.

This study investigated mood adjustment patterns of males and females as they either anticipated an opportunity to retaliate upon a provoker or did not expect such an opportunity. After the provocation, participants browsed through an online newsmagazine that offered equal amounts of good and bad news. Selective exposure to each news article was unobtrusively recorded by time intervals.

We hypothesized that females would aim to dissipate angry moods especially when they expected a retaliation opportunity. This was indeed the case. Those females increased their consumption of positive online news. In contrast, females who did not anticipate a chance to get even tended to reduce their exposure to positive news. Males who anticipated a retaliation opportunity, on the other hand, decreased their exposure to positive news over time and, for the same reason, looked primarily at negative news. In comparison, males who did not expect a chance to get even showed a stronger preference for positive news. These findings render full support to $\mathrm{H}_{1}$. Thus, males and females awaiting a chance to retaliate showed opposite mood regulation patterns.

Furthermore, we expected in $\mathrm{H}_{2}$ that females who anticipate an opportunity to retaliate against the provoker of angry moods would allot more time to media use than females who do not hold this expectation. By this selective exposure behavior, they could distract themselves from adverse feeling states and prevent acting in hostile fashion. For men, the contrary was predicted in $\mathrm{H}_{2}$ as they should be motivated to maintain an angry state in order to get even later. Avoiding distraction through media content, indicated by less time spent on actual news browsing, would indicate this intention. However, females' total news consumption did not differ accordingly. Yet, the provoked females generally spent more time on actual news reading than males, regardless of whether they awaited a retaliation opportunity or 
not. It seems that the females were just more motivated than the males to dissipate their anger after being provoked. For men, the expectation in $\mathrm{H}_{2}$ found some support, but the impact was only marginally significant.

Interestingly, the hypothesized patterns were not significantly affected by the intensity of anger, as had been pondered in $\mathrm{RQ}_{1}$, which could be due to insufficient statistical power for detection of a small effect. However, hypothesis tests and supplementary analyses showed that media consumption is influenced by mood adjustment intentions across time. It could also be established that media choices altered behavior in social situations as the time participants dedicated to positive and negative news toward the end of the news-browsing period, in turn, affected the evaluations they gave to the provoker of their initial angry moods. This is an impressive indication that mood adjustment behaviors and subsequent media selections indeed influence how people behave in a social context.

These results show how the mood adjustment perspective helps to predict selective exposure to media content and how it accounts for selection patterns that mood management theory cannot explain. As it stands, men and women differ in their adjustment goals when it comes to retaliation. This is just one out of many differentiations regarding individuals' adjustment goals. For instance, individuals with different social motivations, such as domination, assertion, or affiliation (e.g., Winter, 1996), are likely to perform dissimilar forms of mood adjustments before they go into any kind of social situation. In addition, goals of impression management (Schlenker, 1980) should affect how individuals prepare themselves in terms of mood adjustment before entering a social setting. For example, a person who wants to come across as sociable and outgoing can accomplish this better in a joyful, exuberant feeling state, for which media can provide well-fitting stimulation. Likewise, anybody who wants to establish the impression of having a thoughtful and eloquent character might want to facilitate such demeanor through exposure to "high-brow" content.

In light of these complexities, it appears that developing the mood adjustment approach into a succinct theoretical model will require considerable additional work. However, given that the approach allows to predict selection patterns that mood management theory cannot explain, it is evident that mood adjustment is a useful complement to the body of mood management research. In order to predict selective exposure to media content, future research should explore the principles that guide the formation of mood adjustment goals. Beyond adjustment goals, the individual anticipations of upcoming situations can be diverse-based on earlier experiences or perceived social norms. Moreover, some idiosyncrasies in the beliefs on what material produces certain mood states are likely to create variation in mood adjustment patterns. Similarly, the time frames that individuals account for in their mood adjustment efforts still call for specification and may also depend on the importance attached to the anticipated activity. The current study sheds light on why individuals allot large portions of the day to media use, why men and women differ in their preferences, and why media use can be functional for daily coping behavior, but many components in this process still await exploration. 
Future research should avoid some limitations of the present study. Treatment checks with additional research participants could provide clearer insight into effects of the experimental manipulations and should use multiple items as dependent measures, which would allow to test internal reliability and to detect other emotional impacts than provocation of anger alone. The current study employed treatment checks that could be incorporated in the main experiment without making the actual research interest too transparent. However, this compromised the clarity of these treatment checks. Ideally, a larger number of respondents in future studies would permit separate manipulation checks and also provide more statistical power in the main procedure. Moreover, if future research should again present a supervisor as provoker, it is preferable to counterbalance the supervisor's gender because it is possible that interactions with the respondent's gender occur.

More insight into mood adjustment is needed for various interests. The present work shows that media use can have other functions than those that are fairly obvious even to the lay media user, such as being informed or in a positive mood. Individuals often employ these functions on intuitive grounds only and might benefit even more if doing so with greater awareness. Furthermore, the current research highlights the importance of choice instead of being simply confronted with some type of message, which should also be of interest for applied research. The mixed findings regarding how music can advance mood in the interest of better learning and for other activities (e.g., Chabris, 1999) could be due to the fact that respondents could not choose the music that worked for them. Finally, public concerns, for instance, about seemingly excessive media consumption (as advocated by Postman, 1985) may overlook the complex functionality that media use offers on a daily basis. Mood adjustment for social and other practical requirements has great value for the individual when it comes to acting appropriately and also for society, which is based on individuals who can coordinate themselves with others.

\section{Acknowledgments}

This project was supported by a grant from the Howard R. Marsh Center at the University of Michigan, Ann Arbor.

\section{References}

Biswas, R., Riffe, D., \& Zillmann, D. (1994). Mood influence on the appeal of bad news. Journalism Quarterly, 71, 689-696.

Brody, L. R. (1993). On understanding gender differences in the expression of emotion: Gender roles, socialization, and language. In S. L. Ablon, D. Brown, E. J. Khantzian, \& J. E. Mack (Eds.), Human feelings: Explorations in affect development and meaning. Hillsdale, NJ: The Analytic Press.

Brody, L. R., \& Hall, J. A. (1993). Gender and emotion. In M. Lewis \& J. M. Haviland (Eds.), Handbook of emotions (pp. 447-460). New York: Guilford. 
Chabris, C. F. (1999). Prelude or requiem for the "Mozart effect"? Nature, 400, 826-827.

Cohen, J. (1988). Statistical power analysis for the behavioral sciences (2nd ed.). Hillsdale, NJ: Erlbaum.

Erber, R., Wegner, D. M., \& Therriault, N. (1996). On being cool and collected: Mood regulation in anticipation of social interaction. Journal of Personality and Social Psychology, 70, 757-766.

Erdfelder, E., Faul, F., \& Buchner, A. (1996). GPOWER: A general power analysis program. Behavior Research Methods, Instruments, \& Computers, 28, 1-11.

Frodi, A. (1978). Experimental and physiological responses associated with anger and aggression in women and men. Journal of Research in Personality, 12, 335-349.

Greenwald, T. (2000, May). Mass distraction: Media consumption in dollars and hours (original source: Veronis, Suhler, \& Associates). Wired, 8, p. 105.

Knobloch, S. (2002). 'Unterhaltungsslalom' bei der WWW-Nutzung: Ein Feldexperiment [translation: 'Entertainment zigzag' while surfing the WWW: A field experiment]. Publizistik, 47, 309-318.

Knobloch, S. (2003). Mood adjustment via mass communication. Journal of Communication, 53, 233-250.

Knobloch, S., \& Zillmann, D. (2002). Mood management via the digital jukebox. Journal of Communication, 52, 351-366.

Knobloch-Westerwick, S. (in press). Mood Management: Theory, evidence, and advancements. In J. Bryant \& P. Vorderer (Eds.), The psychology of entertainment. Mahwah, NJ: Erlbaum.

Masters, J. C., Ford, M. E., \& Arend, R. A. (1983). Children's strategies for controlling affective responses to aversive social experience. Motivation and Emotion, 7, 103-116.

Medoff, N. J. (1979). The avoidance of comedy by persons in a negative affective state: A further study in selective exposure. Unpublished doctoral dissertation, Indiana University, Bloomington, IN.

Mills, J. (1993). The appeal of tragedy: An attitude interpretation. Basic and Applied Social Psychology, 14, 255-271.

Oliver, M. B. (1993). Exploring the paradox of the enjoyment of sad films. Human Communication Research, 19, 315-342.

Oliver, M. B. (1994). Contributions of sexuality to viewers' responses to graphic horror. Journal of Broadcasting \& Electronic Media, 38, 1-17.

Oliver, M. B. (2000). The respondent gender gap. In D. Zillmann \& P. Vorderer (Eds.), Media entertainment: The psychology of its appeal (pp. 215-234). Mahwah, NJ: Erlbaum.

Oliver, M. B. (2003). Mood management and selective exposure theory. In J. Bryant, D. Roskos-Ewoldsen, \& J. Cantor (Eds.), Communication and emotion (pp. 85-106). Mahwah, NJ: Erlbaum.

Oliver, M. B., Sargent, S., \& Weaver, J. B. (1998). The impact of sex and gender-role self-perception on affective reactions to different types of film. Sex Roles, 38, 45-62.

Oliver, M. B., Weaver, J. B., \& Sargent, S. (2000). An examination of factors related to sex differences in enjoyment of sad films. Journal of Broadcasting \& Electronic Media, 44, 282-300. 
O’Neal, E. C., \& Taylor, S. L. (1989). Status of the provoker, opportunity to retaliate, and interest in video violence. Aggressive Behavior, 15, 171-180.

Pearlin, L. I. (1959). Social and personal stress and escape television viewing. Public Opinion Quarterly, 23, 255-259.

Plant, E. A., Shibley Hyde, J., Keltner, D., \& Devine, P. G. (2000). The gender stereotyping of emotions. Psychology of Women Quarterly, 24, 81-92.

Postman, N. (1985). Amusing ourselves to death: Public discourse in the age of show business. New York: Viking.

Rusting, C. L., \& Nolen-Hoeksema, S. (1998). Regulating responses to anger: Effects of rumination and distraction on angry mood. Journal of Personality and Social Psychology, 74, 790-803.

Schlenker, B. R. (1980). Impression management: The self-concept, social identity, and interpersonal relations. Monterey, CA: Brooks/Cole.

Thompson, P., \& O'Neal, E. (1987). Anger, anticipated opportunity to retaliate, and interest in video violence. Journal of Social Psychology, 12, 517-525.

Winter, D. G. (1996). Personality: Analysis and interpretation of lives. New York: McGraw-Hill.

Zillmann, D. (1988). Mood management through communication choices. American Behavioral Scientist, 31, 327-340.

Zillmann, D. (2000). Mood management in the context of selective exposure theory. In M. F. Roloff (Ed.), Communication yearbook 23 (pp. 103-123). Thousand Oaks, CA: Sage.

Zillmann, D., \& Cantor, J. (1976). Effects of timing of information on the mitigating circumstances on the emotional responses to provocation and retaliatory behavior. Journal of Experimental Social Psychology, 12, 38-55.

Zillmann, D., Chen, L., Knobloch, S., \& Callison, C. (2004). Effects of lead framing on selective exposure to internet news reports. Communication Research, 31, 58-81.

Zillmann, D., Hezel, R. T., \& Medoff, N. J. (1980). The effect of affective states on selective exposure to televised entertainment fare. Journal of Applied Psychology, 10, 323-339. 